\title{
DOSSIÊ
}

\section{AS CULTURAS POPULARES NA MUNDIALIZAÇÃO: DESARRUMANDO ESOUEMAS HABITUAIS DE INTERPRETAÇÃO}

\section{POPULAR CULTURES IN THE GLOBALIZED WORLD: DISHEVELING THE ORDINARY INTERPRETATION SCHEMES}

\author{
Mariana Barreto* \\ Michel Nicolau Netto** \\ Vassili Rivron***
}

Quando planejamos este Dossiê uma questão central nos animava: como é possível pensar a cultura popular na contemporaneidade, mesmo sendo muitas vezes compreendida em um arco significativo com a tradição e o arcaico? Em outras palavras, qual a atualidade da cultura popular em um momento no qual a modernidade é confrontada pelas interdependências globais? Ao nos questionarmos, partíamos de dois pressupostos. Em primeiro lugar, que a cultura popular tem sua história, e em cada momento em que se integrou, produziu significados específicos. Assim, a cultura popular que se opôs a uma cul- tura de elite no final da Idade Média (BURKE, 2009), logo encontrou, com a formação do Estado-nação, um novo significado, informado pela constituição da identidade nacional. Basta-nos ler os grandes intérpretes do Brasil para notarmos como a cultura popular das mais diversas formas - alegóricas, trágicas, políticas - se articulou com a nação.

Se a cultura popular tem sua historicidade, isso significa que ela potencialmente carrega para o presente uma carga de seus passados. Nesse sentido, a cultura popular hoje é passível de inscrições em continuidades românticas, deixando-se relacionar a

\footnotetext{
* Doutora em Sociologia pela Universidade Estadual de Campinas - Unicamp. Professora na Universidade Federal do Ceará - UFC (Fortaleza/CE/BR). mariana.barreto@pq.cnpq.br.

* Doutor em Sociologia pela Universidade Estadual de Campinas - Unicamp. Professor do Departamento Sociologia do IFCH/Unicamp (Campinas/SP/BR). mnicolau@unicamp.br.

*** Doutor em Sociologia pela Ecole des Hautes Etudes en Sciences Sociales - EHESS. Professor na Université de Caen Basse Normandie (Caen/FR). vronvassili@gmail.com.
} 
categorias e práticas vistas como tradicionais. Contudo, isso não significa dizer que ela é uma cultura do passado, uma reminiscência de algo esquecido no presente, assim como não remete a uma produção espontânea das classes menos abastadas ou isoladas culturalmente. Em verdade, e este é nosso segundo pressuposto, a cultura popular hoje é uma cultura inserida no tempo presente, que produz sentido em nossa época. 0 Dossiê Cultura Popular Hoje significa, portanto, um chamado para pensarmos as formas contemporâneas como a cultura popular é produzida, distribuída, consumida e estudada, objetivada em manifestações que vinculam-se tanto a tradições passadas quanto a novas práticas e representações. Dessa maneira, é sintomático que este Dossiê seja publicado numa revista cujo lugar de origem, o Maranhão, costuma atribuir a força de sua cultura popular à preservação de seu primado folclórico, tradicional, essencialidade motriz que a integra às dinâmicas regionais, nacionais e internacionais.

A originalidade desta publicação consiste tanto em seu conteúdo, na medida em que anuncia novos referenciais sob os quais a produção do popular hoje pode ser compreendida, como também em sua forma, ao trazer um conjunto heterogêneo de análises sobre temas e objetos da cultura popular. Os cruzamentos de olhares brasileiros e estrangeiros sobre a construção da cultura popular, nos levam a confrontar e considerar as diferentes perspectivas que articulam as dimensões locais, regionais, nacionais, inter e transnacionais, de seus produtos e redes de agentes, quer sejam criadores, produtores, mediadores ou receptores.

Para tanto, devemos entender o processo de mundialização diferentemente da forma como muitas vezes é apresentado: como algo linear, que anula o espaço e desconsi- dera os muitos vínculos sociais intermediários entre o local e o global. Diversos autores que se dedicaram ao tema (como Roland Robertson, Saskia Sassen, Renato Ortiz, Milton Santos, Featherstone, Tomlinson, Appadurai, Giddens) perceberam, de diferentes maneiras, como a mundialização da cultura se refere a movimentos de desencaixe e reencaixe de processos simbólicos que hoje ocorrem entre dinâmicas espaciais cada vez mais distantes. Em verdade, como já mostrava Polanyi (1983), preexistiram, à integração dos mercados nacionais territorializados, redes mercantis de longas duração e distância. 0 mesmo movimento pôde ser observado na circulação dos produtos culturais, para os quais o mercado de extensão nacional não é uma simples etapa intermediária entre as esferas de circulação local e mundiais (CASANOVA, 1999). Thiesse (1999) e Lövgren (1989) explicam não só como as identidades nacionais se formaram nesse mesmo processo, mas vão adiante: fazem ver que o estabelecimento das legitimidades culturais nos âmbitos nacionais mobilizou esquemas de pensamentos elaborados por elites cosmopolitas e suas estratégias de internacionalização e transnacionalização. Isto, sem negar suas declinações locais ou nacionais, mas justamente articulando os processos de apropriação dos bens nacionais e internacionais. Logo, a análise da formação dos campos nacionais não prescinde do exame de suas relações com outros campos nacionais (SAPIRO, 2013); do mesmo modo, o estudo das formações dos campos transnacionais não nos impede de analisar o papel das afiliações, socializações, redes e referenciais nacionais neste processo (GARTH e DEZALAY, 2002).

Desta forma, em um processo de mundialização, a cultura popular passa a se relacionar com novos arcos temáticos. Um deles 
se refere ao tema da diversidade cultural e das questões identitárias. Maria Celeste Mira mostra em Do recalque ao realce: o enegrecimento da cultura popular e o jogo político das identidades uma mudança na relação entre a cultura negra e a cultura popular no Brasil. Enquanto no início do século XX essa relação se marcava pela tentativa de embranquecimento da cultura popular (o recalque do negro), hoje podemos experimentar um momento diferente do realce da cultura negra. 0 trabalho de campo na cidade de São Paulo, sobre os mediadores da cultura popular, permite que Mira demonstre como as chamadas culturas afrodescendentes se tornaram um elemento importante na definição, para esses mediadores, da cultura popular, algo que a autora percebe como referente ao contexto da diversidade cultural. A valorização da diversidade cultural enseja, assim, a maior presença da cultura negra na cultura popular, algo que, não se pode deixar de perceber, é incentivado por razões próprias de um mercado de bens simbólicos. Em outras palavras, o Brasil passa a se "vender", em uma situação de mundialização, como país da diversidade, transformando a cultura negra em um elemento central de valorização de sua identidade, agora bem caracterizada como uma "marca", cujos produtos podem ser consumidos por públicos diversificados e diferenciados.

A relação entre a cultura de matriz afro -brasileira e a cultura popular também se mostra atravessada por amplos processos econômicos, simbólicos e mediáticos no artigo de Edson Farias, Criatividade e tradição no campo das culturas populares. Com um estudo sobre o desfile das escolas de samba, Farias mostra a tensão entre as noções de autoridade comunal (exercida por uma coletividade) e de agência individual (exercida por carnavalescos-artistas e cele- bridades). Neste conflito, aponta o autor, há uma disjunção entre autenticidade e criatividade, sendo que é justamente aí onde as matrizes afro-brasileiras do samba são mobilizadas. São elas que conferem "autenticidade aos fazeres lúdico-artísticos" do desfile, mas o fazem agora de forma relacionada aos conceitos de criatividade e inovação "como núcleos semânticos do aprimoramento da gramática técnico-estética dessa festa-espetáculo.”

Nota-se, portanto, um processo de valorização da cultura popular. Esse recurso é articulado em um segundo arco temático deste Dossiê em relação à patrimonialização e internacionalização da música popular (1950-90).

Vassili Rivron explica em Portraits sonores du Brésil: reconfiguration de l'industrie musicale et différenciation de la musique populaire brésilienne comme objet d'érudition como se opera a reconversão de radialistas, profissionais da fase áurea do rádio, em especialistas consagrados, justamente quando se diferenciavam, objetiva e subjetivamente, os espaços do "popular" e do "folclórico”, para, em seguida, no momento de configuração de um mercado fonográfico no país, estas duas designações se transformarem em categorias musicais diferenciadas da música popular, eleitas como instâncias patrimoniais da cultura nacional.

Porém, simultaneamente à consolidação deste polo nacional e memorial da música popular, surge uma nova geração de músicos que se distingue por suas pretensões "modernizadoras da música popular brasileira”, produzindo categorias como BossaNova, Samba-Jazz ou Tropicália. Esta modernização, na maioria das vezes, está relacionada ao estabelecimento de vínculos profissionais e artísticos com um circuito musical fora do Brasil, seja pela incorpora- 
ção de novas práticas e referências artísticas, políticas ou comerciais, seja pela circulação internacional de obras e artistas. Vemos assim como a valorização e atualização dos esquemas de pensamento da cultura popular sugerem, por um lado, uma distinção interna das redes nacionais e, por outro, uma deferência externa, com o reconhecimento da música popular brasileira nos circuitos internacionais. É o que demonstra Gabriel Muniz Improta França em A cozinha afro-brasileira no samba-jazz: a cultura popular mundializada e o samba moderno. A consagração da singularidade da música brasileira é reinterpretada a partir das apropriações de práticas, especificações e recursos musicais estrangeiros. 0 apelo à modernização da música brasileira - levado a efeito pela reorganização da indústria musical local em torno do advento do disco Long Play, da consolidação das emissoras de televisão e, posteriormente, dos festivais musicais -, deu lugar, a partir do final dos anos de 1950, a propostas concorrentes de renovação do samba, entre as quais várias que mobilizaram referências e recursos da música erudita contemporânea, cosmopolita, e de estilos internacionais consagrados como o Jazz.

Numa outra chave compreensiva deste processo de internacionalização da música popular brasileira, e apontando para a perspectiva de formação de um campo transnacional da música popular, encontra-se a discussão proposta por Andréa B. Leão e Mariana Barreto, em Cultura nacional-popular e circulação transnacional: Brasil e Angola no Projeto Kalunga. 0 desafio perseguido por ambas é o de demonstrar que a circulação mundial de certos produtos da cultura popular não deve ser pensada apenas em termos de consagração de talentos artísticos, mas também como opor- tunidades para a construção de redes de interdependências que possibilitam a sua circulação. Tanto do ponto de vista econômico (criação de novos circuitos musicais, novas redes animadas por festivais internacionais, envolvendo majors de diferentes segmentos das indústrias culturais locais e mundiais), quanto do ponto de vista político (as diplomacias culturais estatais ou militantes, na forma das caravanas musicais, excursões internacionais, festivais de música), esses projetos artístico-musicais passaram a desempenhar um papel significativo no incremento da força da música brasileira para além de suas fronteiras nacionais. A eficácia simbólica de operações, como as do Projeto Kalunga, é entendida pela convergência de interesses diversificados (econômicos, políticos, culturais e artísticos), assim como pelo esboço de uma geopolítica cultural onde se negociam as modalidades relacionais e as hierarquias de legitimidade entre gêneros, etnias e nações.

Não deixamos de apreender, portanto, que a validação e valorização das músicas nacionais nos espaços internacionais se deram pela constituição de espaços transnacionais. Identidades regionais, continentais ou pan-étnicas (latina, africana, centro -americana, caribenha etc.), a eficácia do "encontro entre culturas diversas", confundem-se e naturalizam-se de forma problemática. Nesta perspectiva, Alix Bénistant em Industrie musicale et (en)jeux d'échelles: les passages du local au global dans la "latin music" produite à Miami expõe a configuração de um hub fonográfıco industrial latino concentrado em Miami. Ele descreve as complexas estratégias traçadas por estas indústrias, estabelecidas em escalas local, regional, nacional e mundial, para a construção de um mercado da música latina, cuja diáspora está baseada nessa cida- 
de global (frequentemente designada como uma "capital latino-americana", pelo fluxo intenso e pela circulação acelerada de pessoas e produtos originários das Américas Central e do Sul). Bénistant dedica-se à interpretação de uma das estratégias mais conhecidas quando da implantação dos conglomerados internacionais em novos territórios. Isto é, adaptar-se a minima às práticas locais, articulando referências culturais locais e serviços globalmente padronizados (ABÉLÈS, 2008).

A relação entre cultura popular e mundialização desafıa a sociologia contemporânea em densas confıgurações. Uma delas informa o terceiro arco temático dos artigos deste Dossiê: a relação entre cosmopolitismo e classes sociais. Os temas propostos, as fontes utilizadas e os objetos analisados nos permitem observar recorrências nas formas como a cultura popular se organiza. A circulação de ideias, obras, criadores e agentes, as trocas que se dão nesses movimentos, as conversões realizadas por instituições e produtores, constituem um indicador da existência de campos transnacionais para as produções artísticas. De modo idêntico, revelam a importância do trabalho dos mediadores empenhados na produção e circulação dos bens culturais, apontam para a necessidade de considerarmos certa porosidade nos limites das fronteiras entre os campos, visto que estão atravessados por sistemas de intermediação que organizam as modalidades de circulação, conversão e recepção dos produtores e seus produtos, operando de forma plural, segundo as regiões de origem dos (entre os) diferentes campos (ROUEFF, 2013; LIZÉ, NAUDIER e ROUEFF, 2011).

Com o propósito de iluminar aspectos desta perspectiva analítica, os dois últimos artigos fecham nosso Dossiê ampliando as possibilidades para repensarmos os objetos da cultura e suas internacionalizações, ressituados na história de suas formações nacionais. Em 0 gosto pelo mundo: a globalização da cultura apreendida pelo cosmopolitismo estético-cultural dos jovens na França, Vicenzo Cicchelli e Sylvie Octobre estão atentos à observação concreta das preferências culturais dos jovens franceses, distribuídos em função de suas propriedades sociodemográficas que diferenciam uma amostra representativa dessa população; se interessam pelos seus gostos por produtos culturais globais difundidos em larga escala, a fim de discutirem a relação entre estes atores ativos no processo de mundialização e um certo "cosmopolitismo estéticocultural”. Nos fenômenos de internacionalização dos repertórios de consumo observados, novas hierarquias se estabelecem, antigas classificações, segmentações, se transformam, alterando as relações entre os consumidores e os produtos consumidos. 0 "cosmopolitismo estético-cultural" se realiza via sistemas de intermediação onde participam novos agentes (organizando modalidades inéditas de circulação, controlando as condições da oferta e da recepção, prescrevendo modos de apreciação legítimos e ilegítimos etc).

0 artigo de Michel Nicolau Netto e Juliana Miraldi encerra este Dossiê também sob uma perspectiva relacionada ao cosmopolitismo, visto a partir do mercado global de turismo. Em Turismo de luxo: a produção do destino e a denegação do social, os autores notam como o turismo se espalha globalmente, tornando-se um elemento próprio da vivência da globalização. Ao mesmo tempo, não é mais distintivo viajar, mas sim a maneira de se viajar. 0 mercado de turismo de luxo então ganha força, e os próprios destinos se tornam elementos de distinção. 
Em outras palavras, os autores mostram como os lugares são construídos social e materialmente como forma de classificação de um gosto globalizado. Da cultura popular ao gosto globalizado não há um continuum, mas um emaranhado de cruzamentos de espaços e significações. É esta visão de uma mundialização da cultura, ao mesmo tempo atenta à sua diversidade e à sua complexidade, que o leitor encontrará neste Dossiê.

\section{Referências}

ABÉLĖS, M. Anthropologie de la Globalisation. Paris: Payot, 2008.

APPADURAI, A. Modernity at Large: Cultural Dimensions of Globalization. Minneapolis: University of Minnesota Press, 1996.

BOURDIEU, P. Manet: Une révolution symbolique. Paris: Raisons d'Agir/Seuil, 2013.

BURKE, P. Popular Culture in Early Modern Europe. Farnham, Burlington: Ashgate, 2009.

CASANOVA, P. La République Mondiale des Lettres. Paris: Seuil, 1999.

DEZALAY, Y e GARTH, B. G. The Internationalization of Palace Wars: Lawyers, Economists, and the Contest to Transform Latin American States. Chicago: University of Chicago Press, 2002.

FEATHERSTONE, M. (Org). Cultura global: nacionalismo, globalização e modernidade. Petrópolis: Vozes, 1999.

GIDDENS, A. As consequências da modernidade. São Paulo: UNESP, 1991.

LIZÉ, W.; NAUDIER, D.; ROUEFF, O. Intermédiaires du Travail Artistique: à la Frontière de l'Art et du Commerce. Paris: Département des Études, de la Prospective et des Statistiques, 2011.

LÖFGREN, 0. The Nationalisation of Culture. Ethnologia Europæa, n. XIX, p. 5-23, 1989.

POLANYI, K. La Grande Transformation. Gallimard: Paris, 1983.
ORTIZ, R. Universalismo e diversidade: contradições da modernidade-mundo. São Paulo: Boitempo, 2015. Mundialização e cultura. São Paulo: Brasiliense, 1994.

A moderna tradição brasileira. São Paulo: Brasiliense, 1988.

ROBERTSON, R. Globalization: Critical Concepts in Sociology. London: Routledge, 2003.

ROUEFF, 0. Les homologies structurales: une magie sociale sans magique? La place des intermédiaires dans la fabrique des valeurs. In: COULANGEON, P. et al. Trente Ans Après La Distinction, de Pierre Bourdieu. Paris: La Découverte, 2013. p. 153-164.

SAPIRO, G. Le champ est-il national? La théorie de la différenciation social au prisme de l'histoire globale. Actes de la Recherche en Sciences Sociales, Théorie du Champ. Paris: Seuil, n. 200, p. 71-85, Décembre 2013.

SASSEN, S. A Sociology of Globalization. New York: Norton, 2007.

THIESSE, A. M. La Création des Identités Nationales. Europe XVIIIe - XXe siècle. Paris: Seuil, 1999. TOMLINSON, J. Globalization and Culture. Cambridge: Polity Press, 2001. 